\title{
MEMORIA ELÁSTICA UNA EXPERIENCIA EN DESARROLLO DE PRODUCTO
}

\section{ELASTIC MEMORY A DEVELOPMENT PROJECT EXPERIENCE}

Adrián Sosa | adrian.sosa.poncetta@gmail.com

Taller de Diseño Industrial IV B. Facultad de Bellas Artes. Universidad Nacional de La Plata. Argentina

Recibido: 19/2/2019 | Aceptado: 16/5/2019

\section{RESUMEN}

Opiniones, pensamientos e ideas personales se articulan a través de un escrito que recoge la experiencia de un proyecto pensado para la sustitución de importaciones, en el cual se mencionan datos y referencias, tanto pasadas como actuales. Una reflexión sobre un país que durante más de doscientos años sigue intentando y quiere ser parte de la historia mundial desde una perspectiva industrial y generadora de conocimiento.

\section{Palabras clave}

Industria; sustitución de importaciones; diseño; políticas públicas; cultura

\section{ABSTRACT}

Opinions, thoughts, and personal ideas, through a story that gathers the experience of a project, designed to substitute imports. In which, data and references, both current and the moment lived. A reflection about a country, that for more than two hundred years, continues to try, and wants to be part of world history from an industrial perspective and generating knowledge.

\section{KEYWORDS}

Industry; import substitution; design; public politics; culture 
Al momento de empezar a escribir este trabajo, se anunciaba en los medios de comunicación argentinos el cierre de la empresa Metalpar, fabricante de carrocerías de colectivos que, de esa manera, dejaba a seiscientos empleados directos sin trabajo (Terrile, 2019). Sí, el colectivo, que es considerado un invento argentino y que es uno de los métodos más ágiles de transporte público para zonas urbanas. Es por esta razón que, en este caso, parece pertinente interpretar y resignificar lo privado como público: la pérdida de un referente industrial tiene impacto directo en el plano social. Este suceso está inmerso, además, en un contexto político en el que la conducción pública está gestionada por un equipo gerencial proveniente del ámbito privado. Zygmunt Bauman (2007) anticipaba el futuro de la política que vivimos actualmente y lo describía de esta forma:

La práctica gerencial de generar una atmosfera de crisis, o de presentar como un estado de emergencia una situación común y corriente, se considera el método preferido, por su gran eficacia, para persuadir a los empleados de que acepten plácidamente los cambios más drásticos que destruyen todas sus ambiciones y perspectivas, e incluso su propio medio de vida. Declarar un estado de emergencia... y seguir al mando parece ser la cada vez más popular receta gerencial para que su autoridad sea incuestionable y para salir impune de los ataques más indigeribles e irritantes que lanza contra el bienestar de sus empleados (pp. 132-133)

El método enunciado por Bauman describe perfectamente a la actual dirigencia política argentina, que lejos de permitir y de alentar el diálogo, se presenta como el único camino posible en el que un grupo de notables promete la salvación, mientras que el reclamo social y gremial característico de la década anterior aparece sometido al silencio.

Como política de estado, la producción de bienes debe ser incentivada y acompañada, la promoción industrial vista como pilar estratégico del desarrollo debe ser el foco de todo gobierno. En este sentido Pablo Ungaro (2015) escribe:

Se observan políticas públicas que, pese al negativo contexto internacional, [...] benefician a toda la sociedad, porque el destino del diseño, no puede ser otro que el destino del país. Nos va bien porque hay intervención estatal, porque producimos y nos desarrollamos con diseño; si elegimos políticas de libre mercado y le dejamos el control a las iniciativas privadas, no precisaremos diseño porque tampoco tendremos producción industrial (p. 20).

Si miramos diez años hacia atrás, las políticas estatales impulsadas por el gobierno en ese momento hicieron que la burbuja inmobiliaria que desató la crisis financiera global del 2008 pasara por la Argentina sin dejar huellas fuertes en la economía local, mientras que en Estados Unidos el The New York Times publicaba: 
Anheuser-Busch accedió el domingo pasado por la noche, a venderse a la cervecera belga InBev por alrededor de 52 billones de dólares. Personas informadas sobre el asunto dijeron: pusieron el control del mayor fabricante de cerveza de la nación y un elemento de la cultura estadounidense en manos de un rival europeo (de la Merced, 2008, s. p.).

Para el año 2010 la Argentina era considerada un País Emergente y la economía había registrado un incremento del producto bruto interno (PBI) con respecto al año anterior del 9,2\% (INDEC, 2010, p. 31). Este crecimiento fue impulsado por la expansión del consumo y de los sectores productores de bienes y servicios.

Respecto al consumo se dio una mayor alza de los bienes no durables, que de los durables. Al incremento de las ventas de los alimentos y otros productos de primera necesidad, se agregaron mejoras en los sectores de indumentaria y electrodomésticos. Resultó posible por un mantenimiento del empleo al que se le agregó la implementación de la asignación universal por hijo, logrando un bolsillo más amplio de los sectores más postergados de la economía. Y en cuanto al empleo, lejos estuvo de ubicarse en línea con las primeras estimaciones, que hablaban de una destrucción del mismo. Así el año cerró con un desempleo en leve baja ubicándose en 8,4\% (Arfaras, 2010, s. p.).

Durante este incremento del consumo, me encontraba trabajando como encargado del Departamento de Ingeniería de Empaque de una multinacional líder mundial en recipientes herméticos. Allí tuve la posibilidad de liderar un proyecto a través del cual se buscaba sustituir la importación de los productos estrella de la compañía para fabricarlos localmente con proyección exportadora a países limítrofes. Para abril de 2010, las ventas en la región sumaban al negocio de la empresa unos 2.2 millones de dólares y los principales medios de comunicación anunciaban con bombos y platillos el desembarco de la empresa y la futura fabricación a nivel local. Los productos en cuestión eran una familia de contenedores plásticos que ya habían sido manufacturados anteriormente en el país en los años ochenta y noventa, pero que con la llegada de la crisis del año 2001 dejaron de ser rentables para la empresa, que se retiró de la Argentina.

En mi carrera profesional nunca había encarado un proyecto de estas características. Tal es así que la posibilidad de hacerlo en ese momento en particular me llenaba de orgullo, ya que sentía que no solo aceptaba un nuevo desafío como Diseñador Industrial, sino que también ayudaba al país a generar trabajo e identidad, y a ganarse un lugar en la región. 


\section{SUSTITUCIÓN DE IMPORTACIONES}

La propuesta presentada a la Dirección de Abastecimientos de mi empleador para avanzar con el preproyecto se basó en dos etapas. La primera consistía en evaluar posibles proveedores de inyección, ya que el volumen a fabricar todavía no justificaba la instalación de una operación propia en el país. En la segunda etapa, una vez afianzada la tercerización en la que el canal de venta, la logística local y regional estuvieran desarrollados, sería posible avanzar en firme con una inversión industrial de mayor envergadura.

Con la estrategia validada, el paso siguiente sería generar contacto con la empresa que había servido de soporte al negocio con anterioridad y, para sorpresa de todos, la misma ya no brindaba el servicio de inyección a terceros, sino que había apostado al diseño y a la construcción de herramental, para realizar un restyling de su línea de productos propios. Así, había casi duplicado su capacidad productiva (de 13500 m2 cubiertos a $22000 \mathrm{~m} 2$ cubiertos), dedicándose exclusivamente a la fabricación de electrodomésticos de línea blanca. Esta compañía, como tantas otras, pudo ampliar y diversificar su producción gracias al marco socioeconómico del país.

Era pertinente, entonces, comenzar la búsqueda de posibles proveedores, que tuvieran la posibilidad de fabricar piezas de gran tamaño y con capacidad de inyección de plástico de más de 350 toneladas. A partir de ahí, comencé a recorrer el conurbano bonaerense y fui descubriendo una gran cantidad y variedad de pequeñas y medianas empresas que se dedicaban al rubro y que, pudiendo o no brindar el servicio, maravillaban mis ojos con el nivel de desarrollo en los productos que fabricaban. Muchas, en sus vitrinas, exhibían orgullosas, juguetes, tapas, envases, piezas automotrices, entre otros productos, que habían sido fabricados en los años cincuenta, sesenta y setenta, y que en su gran mayoría eran desconocidos para mí. Esta era la forma que tenían de hablar de calidad, capacidad intelectual y herencia industrial. No es casual entonces que Ana Luisa González Arévalo (2009) sitúe el proceso de la Industrialización vía Sustitución de Importaciones (ISI) en esos años, comenzando en la década del cincuenta, con su mayor intensidad hacia inicio de los sesenta, para su posterior interrupción a fines de los setenta.

De las cerca de treinta empresas visitadas, la gran mayoría tenía la capacidad comprometida y lamentaba no poder acompañarnos en el proyecto. No obstante, estas compañías querían mantener el contacto debido a que en los próximos años tenían como parte de sus planes de inversión, ampliar la capacidad productiva y, de esta manera, hacer crecer sus negocios. Claro está que este pensamiento venía de la mano de la idea de fomento industrial y de consumo que se respiraba en el aire en aquel momento. Ariel Bonfanti (2015) analiza y compara la evolución de la capacidad industrial instalada en el sector manufacturero: 
Hasta el 2003 había solo 80 parques industriales, pero desde esa fecha hasta la actualidad se han incrementado hasta llegar a 371 en todo el territorio nacional, lo cual ha representado la creación de más puestos de trabajo, el funcionamiento de casi 4.000 nuevas empresas y la ocupación de cerca de 20.000 hectáreas que en épocas pasadas estaban sin ocupar o abandonadas y que hoy están destinadas al uso industrial (p. 15).

Finalmente, luego de muchas entrevistas y de cinco meses de trabajo, presenté un informe donde recomendaba avanzar en las negociaciones con dos empresas, una ubicada en el parque industrial de Pilar, dedicada a proveer inyección de plástico para la industria del packoging de cuidado personal, y otra del parque industrial El Pato, proveedora de la industria autopartista. Ambas con tecnología y con capacidad industrial y humana instalada, pero que por la ubicación geográfica de los parques permitían un rápido acceso a autopistas, trenes e incluso a los puertos comerciales ubicados al norte y sur de la ciudad de Buenos Aires. Esto confería, por un lado, posibilidades de abastecimiento de producto por vía asfáltica o férrea (en caso de que fuera requerida) y, por otro lado, acceso a la vía marítima para la exportación.

A fines de 2010 dejé la empresa para afrontar un nuevo desafío como líder de innovación en una compañía cervecera, razón por la cual no pude ver el resultado del trabajo realizado. Sin embargo, pude entender que si bien las crisis o los modelos económicos pueden dañar, frenar, molestar y hasta oponerse a la visión productiva de un país, por debajo, queda una siembra de capacidades latente a la espera de que las condiciones vuelvan a ser favorables y permitan que el desarrollo florezca nuevamente.

\section{REALIDAD ACTUAL}

Podemos hablar, entonces, si tenemos en cuenta los vaivenes económicos que se sucedieron en nuestro país, de lo que denominamos memorio elástico industrial argentina. Esta memoria elástica, basada en una sofisticada cultura industrial, es independiente del nivel de desarrollo tecnológico y se encuentra consolidada en el país. Esto sugiere que es posible rediseñar y actualizar la matriz productiva a los tiempos que corren, para volver a activarla a partir de políticas públicas.

Andrea Saba (2000) advierte que excluir la información, la gobernabilidad y la confianza de los modelos interpretativos económicos, termina generando una falsa cultura analítica en relación con los estudios que pueden hacerse sobre la industria. Por esta razón, no alcanza solamente con impulsar el crédito o con generar planes de fomento -herramientas básicas para la promoción industrial-, sino que el Estado debe convertirse nuevamente en garante de algunos bienes sociales intangibles, como son la certeza, la seguridad y la libertad, y debe atender a estos en todos los niveles sociales, culturales y económicos. A partir de estas bases es posible proyectar e imaginar un futuro sustentable, que permita a la vez generar las condiciones para que esta industria dormida, vuelva a despertar. 
Al mirar el presente, nos encontramos en una situación en la que ya estuvimos, que ya conocemos. La misma está asociada a la escasa diversificación de las exportaciones argentinas, que de la mano de la especialización primario exportadora, restringe las posibilidades de crecimiento industrial y económico a las fluctuaciones de la demanda externa. En este contexto, la industria nacional pierde fuerza y confianza, y los capitales que deberían asociarse a esta prefieren la inversión en activos financieros en lugar de productivos.

Masahiko Aoki (1990) interpreta a la industria japonesa como un conjunto donde economía y cultura mantienen una relación lógica y coherente. Esto supone que la empresa toma un papel integral dentro de la sociedad en la que se encuentra inmersa. Para lograr el desarrollo económico como nación, entendido y aceptado desde la revolución industrial, tanto global como históricamente, debemos dar lugar a la incorporación de conocimiento y tecnología a la producción. Para traducir este ideal a hechos concretos, nuestra sociedad debe primero asumirlo como propio, para que luego de aplicar dicho conocimiento en el plano económico-social, pueda comenzar a pensar en cómo distribuir el resultado de ese conocimiento y volverlo tangible. Dejar de lado esta línea de pensamiento significa volver a repetir el pasado y, por consiguiente, volver a cometer los mismo errores.

Es por esto que debemos dejar atrás definitivamente la dicotomía sarmientina que nos atraviesa culturalmente, para entender que la idea de nación es una expresión dinámica que puede y debe ser acompañada y sostenida en el tiempo, bajo una visión unificada que atienda a todos los sectores económicos del país.

En las economías con un avanzado nivel de desarrollo hay un equilibrio, que no solamente opera a niveles de comercio internacional, sino que también abarca a la calidad e incluso a la composición de las exportaciones con respecto a las importaciones. De esta manera, el balance, se vuelve más estable y predecible.

Entonces, ¿por qué en la Argentina se sigue discutiendo acerca del modelo económico a seguir? Esta pregunta deja en evidencia una falta de acuerdo políticosocial en el que todos los niveles deben consensuar un plan, para conformar un país integral. Dentro de este acuerdo es fundamental promover la industria y el diseño, porque allí, además del empleo real, reside el complejo productivo que es el encargado de articular el conocimiento e integrarlo de forma permanente en el plano económico-social. No debemos olvidar que el diseño es la herramienta por excelencia con la cual implementar políticas estatales de producción industrial, que den forma a la innovación a través de objetos de consumo. Para Peter Drucker (1997) la innovación como estrategia industrial debe comprender el ciclo de vida de los productos, para así, alimentar la innovación constante. En la producción de bienes de consumo, de creación de objetos, la innovación es la piedra fundamental sobre la cual construir. Por su parte, Ana Bocos (2013) entiende a los objetos no solo como el resultado del desarrollo natural del diseño industrial, sino también como un vehículo de mensajes, en el que se establece como un conjunto indispensable para constituir una herramienta de reafirmación del ser nacional «lo nuestro como 
valor» (p. 19). Con ambos conceptos en mente debemos entender y aceptar, que industria, innovación y diseño son la base del crecimiento sostenido y sustentable que permiten que la empresa productora de bienes genere demanda de empleo. En ese sentido, el conjunto diseño-producción aporta cultura e identidad a la sociedad no solo en el plano industrial, sino también en el cotidiano, al que todo el entramado social tiene acceso. El diseñador, no solo interpreta la cultura, sino que la genera.

La dicotomía instalada por Sarmiento, que se continúa resignificando en nuestra sociedad -y que hoy se encuentra resumida en la metáfora de la grieta-, sigue condicionando al país al momento de tomar decisiones de Estado, que resulten sustentables en el tiempo. Para poder revertirlo, debemos, como responsables que somos de nuestro propio destino y para lograr encontrar nuestro lugar en un contexto global tan volátil, dejar atrás definitivamente el binomio histórico y reemplazarlo por una estructura basada en más de un eje, cuyo sostén depende de la articulación de un conjunto de factores en juego. Cuantos más vectores aporten al conjunto, más firme va a ser la estructura resultante.

Podemos comenzar con diseño, innovación, producción, calidad, economía política, identidad regional y nacional; conceptos existentes en nuestra cultura que rápidamente pueden volver a enfocar al país en el camino sustentable, que traiga beneficios a la sociedad en su totalidad. Este ideario, resulta ser, entonces, el punto de partida para proyectar de manera conjunta políticas públicas y un desarrollo social sostenido. No pretender crear o imponer una receta, sino simplemente plantear que debemos dejar atrás la discusión sobre modelos y trasladar el debate al plano económico-social en el que, a partir del equilibrio y de la integración como política pública industrial, podamos construir ese país que soñamos todos.

\section{REFERENCIAS}

Aoki, M. (1990). La estructura de la economía japonesa. Ciudad de México, México: Fondo de la Cultura Económica.

Arfaras, F. (22 de marzo de 2010). En el año de la crisis, Argentina fue la quinta mejor economía del G-20. Ámbito. Recuperado de https://www.ambito.com/en-el-ano-lacrisis-argentina-fue-la-quinta-mejor-economia-del-g-20-n3613653

Bauman, Z. (2007). Vida de Consumo. Ciudad Autónoma de Buenos Aires, Argentina: Fondo de Cultura Económica.

Bocos, A. (2013). El diseño en el nuevo paradigma productivo. Tableros, (4), 18-22. Recuperado de http://papelcosido.fba.unlp.edu.ar/pdf/revistas/tableros/Tableros-4.pdf

Bonfanti, F. A. (2015). Análisis del modelo de industrialización por sustitución de importaciones en América Latina y en Argentina. Una mirada hacia la realidad industrial actual en Argentina. Revisto Geográfico Digitol, 12(24). doi: 10.30972/geo.12242164

De la Merced, M. J. (14 de julio de 2008). Anheuser-Busch Agrees to Be Sold to InBev [Anheuser-Busch Accede a Ser Vendida a InBev]. The New York Times. Recuperado de https://www.nytimes.com/2008/07/14/business/worldbusiness/14beer.html

\section{TABLEROS}

N. ${ }^{\circ} 10$ | octubre 2019 | ISSN 2525-1589 
INDEC, (2010). Informe Económico No 74 Cuarto Trimestre de 2010 (31). Recuperado de https://www.economia.gob.ar/peconomica/informe/informe74/ version_completa.pdf

Ducker, P. (1997). La Innovación y el Empresariado Innovador. La Práctica y los Principios. Ciudad Autónoma de Buenos Aires, Argentina: Sudamericana.

González Arévalo, A. L. (2009). El proceso de sustitución de importaciones en América Latina: el caso de México, 1940-198. Recuperado de http://www.eumed. net/libros-gratis/2009a/513/EL\%20PROCESO\%20DE\%20SUSTITUCION\%20DE\%20 IMPORTACIONES\%20EN\%20LA\%20INDUSTRIA\%20LATINOAMERICANA.htm

Saba, A. (2000). El Modelo Italiano. La Especialización Flexible y los Distritos Industriales. Recuperado de https://repositorio.cepal.org/handle/11362/31097

Terrile, S. (28 de febrero de 2019). Las razones detrás del cierre de Metalpar, que despedirá a 600 empleados. Lo Noción. Recuperado de https://www.lanacion.com.ar/ economia/crisis-cerro-metalpar-razones-detras-centenares-despedidos-nid2224316

Ungaro, P. (2015). El destino del diseño y el destino del país. Tableros, (6), 19-22. Recuperado de http://papelcosido.fba.unlp.edu.ar/pdf/revistas/tableros/Tableros-6.pdf 